${ }^{1}$ Departamento de Producción Animal, Facultad de Veterinaria, 28040 Madrid and ${ }^{2}$ Centro de Selección Animal (CENSA), Somió, Asturias, Spain

\title{
Estimation of direct and maternal genetic parameters for preweaning traits in the Asturiana de los Valles beef cattle breed through animal and sire models
}

\author{
By J. P. GUTIERREZ ${ }^{1}$. J. CANON ${ }^{1}$ and F. GOYACHE ${ }^{2}$
}

\begin{abstract}
Introduction
'Asturiana de los Valles' is a local beef cattle breed mainly distributed in the central and western part of Asturias but it is also present in other parts of Spain (CANON et al. 1994). Asturias is a region located in the Cantabric branch in the north of Spain where animals are bred in very hard conditions on the steep slopes of the highlands. The importance of the breed has increased dramatically, mainly due to two reasons: the breed has one of the leanest carcasses in Europe (VALLEJO et al. 1993), and there is a growing demand for semen for crossbreeding with Holstein Friesian in Spain (about 300000 per year).

Most of the animals are kept on an extensive grazing pasture system for 200 days/year. There are even some farms close to the sea where the animals are managed under a regular confinement semi-intensive system to breed animals with the muscular hypertrophy syndrome.

Performance recording is organized in 25 centres with an average of 22 herds in each, grouped by proximity and production system. The mean farm size is very small which makes the maintenance of sires difficult and consequently, leads to much artificial insemination (about 25\%, from 9 to $57 \%$ depending on areas), generating close connections among animals.

During the last three decades, the number of animals with muscular hypertrophy syndrome has increased, and almost all the sires for artificial insemination, and many of the dams, now have this trait.

Records have been collected over the last eight years and there now is an acceptable data set which may provide the knowledge of the parameters required, for genetic evaluation of the animals.

There is considerable literature about several genetic parameter estimates concerning preweaning traits in some important beef cattle breeds, which provides a lot of useful information to work with (see for a review, MOHIUDIN 1993). However, some local breeds such as this one, have an important genetic base and an increasing use, but there are many issues still to be investigated (TAWAH et al. 1993).

Traits measuring pre-weaning performance are usually affected by their maternal influence which is often highly correlated with the direct genetic effect of the calves. Moreover, when models allowing for maternal effects are fitted estimation of variance components has become one much-debated issue and is still unresolved. The objective of this project was to estimate the variance components in this breed for the main pre-weaning traits.
\end{abstract}

\section{Material and methods}

Data

All the records came from the Breeder Association (ASEAVA) having been collected since the initiation of recording in 1987 until 1994 were used. Three variables concerning pre- 
Table 1. Means, standard deviation, coefficient of variation and

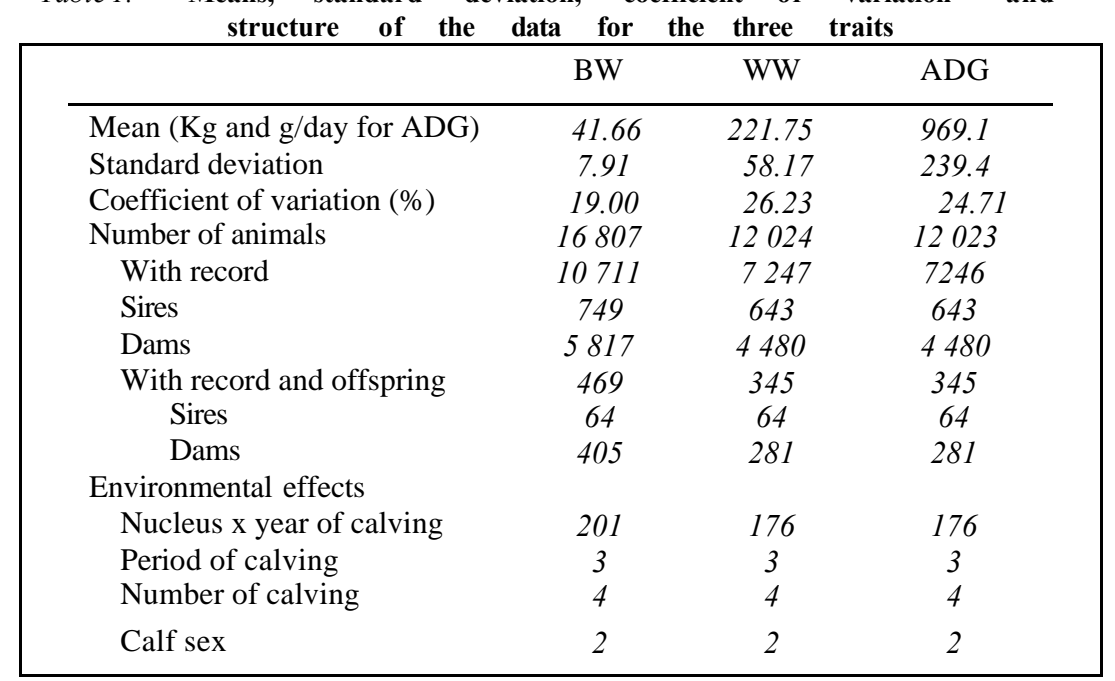

weaning performance were analysed: birth weight (BW), weaning weight (WW) and preweaning average daily gain (ADG). The original data set consisted of 18505 records. Categories eliminated were: 1) twin calving, 2) identification errors,3) those from animals with ambiguous birth date and 4) those records outside 3.5 standard deviations from the mean values. The final data set used for an animal model consisted of 10711,7247 and 7246 records, respectively, for birth weight, weaning weight and pre-weaning average daily gain. The structure of the data is shown in Table 1 . It must be noted that very few animals with offspring had their own record, making it difficult to break down the correct variance components when an animal model including maternal effects was used. When using a sirematernal grandsire model, obviously, the number of records was reduced to 3459, 2460 and 2459 , respectively, for the three traits.

\section{Methods}

Three variables were analysed for genetic parameters using an univariate REML procedure: birth weight $(\mathrm{BW})$, weaning weight (WW) and pre-weaning average daily gain (ADG). All the models included the same four fixed effects: nucleus by year of calving, period of calving, number of calving and calf sex effects (Table 1). Both weaning weight and average daily gain included the age at weaning in their models as a linear and quadratic covariable. Regarding the random effects, seven different models were fitted:

1. An animal model with additive genetic effect being the only random effect in the model besides the residual.

2. As 1 , but including also the maternal genetic effect with a variance-covariance matrix for this effect being proportional to the additive numerator relationship matrix.

3. As 2, but including also the covariance between both direct and maternal genetic effects.

4. The whole animal model which is as 3 , but with a third random effect besides the residual, the permanent environment maternal effect (CANTET et al. 1993).

5. A sire model with the sire effect being the only random effect in the model besides the residual.

6. A sire and maternal grandsire model, allowing for the maternal covariance between maternal and direct genetic effects components estimation. 
7. A sire, maternal grandsire and dam nested model (SHI et al. 1993) allowing to estimate all the components appearing in 4.

Parameters estimated were:

$$
\begin{gathered}
\sigma^{2}=\sigma_{a}^{2}+\sigma_{a m}+\sigma_{m}^{2}+\sigma_{e}^{2} \\
h^{2}=\sigma_{a}^{2} / \sigma^{2} \\
m^{2}=\sigma_{a}^{2} / \sigma^{2} \\
c^{2}=\sigma_{c}^{2} / \sigma^{2} \\
r_{a m}=\sigma_{a m} /\left(\sigma_{a} \sigma_{m}\right)
\end{gathered}
$$

$\sigma_{2}$, the phenotypic variance; $h^{2}$, the heritability; $\mathrm{m}^{2}$, the proportion of phenotypic variance due to maternal genetic effect, maternal heritability; $c^{2}$ the proportion of phenotypic variance due to maternal permanent environmental effect; $r,$, , the correlation between direct and maternal additive genetic effects.

All the runs were carried out using the DFREML program written by MEYER (1991). All of them were re-started to avoid a local maximum until reaching the global one.

\section{Results and Discussion}

Estimates of the main genetic and environmental parameters obtained are shown in Table 2 . Estimates of heritabilities of birth weight agree with the values in the literature for other beef cattle breeds (See for a review, MOHIUDDIN 1993). However, heritabilities of weaning weight and average daily gain were higher than common literature values and, in spite of what was expected, also higher than birth weight heritabilities for the same population. On the other hand, there is a close agreement between models for birth weight but less for weaning weight and average daily gain. These contradictory results suggest that estimates for these latter traits are less precise.

The heritability estimate for birth weight under the model $1(0.57)$, was clearly biased by fitting the additive genetic as the only random effect besides the residual. WALDRON et al. (1993) concluded that animal models which ignored maternal effects tend to overestimate direct heritability. So, when maternal influence was included in the model, this heritability estimate was 0.32 and the maternal heritability 0.13 . Very slight changes occurred when adjusting models 3 and 4, confirming the results from model 2. The agreement between results from different models can be easily explained by the lack of a covariance between direct and maternal genetic effects for this trait. Finally, the light differences observed when using the sire model were explained by the reduction of records in preparation of the data.

Direct heritability was higher than maternal heritability for the weaning weight trait, with high negative correlation between these effects, as suggested by recent reports (CANTET et al. 1993). Weaning weight and average daily gain show similar results between them, probably due to the similarity of the traits, since weaning weight is a linear combination between the birth weight and the average daily gain $(\mathrm{WW}=\mathrm{BW}+$ Age $\times$ ADG). Hence, the results for the weaning weight trait must be very similar to those for average daily gain but slightly modified towards those for the birth weight trait.

Even though pre-weaning traits can be clearly affected by the maternal influence, sometimes it is not easy to determine such influence due to the genetic correlation between maternal and direct genetic effects. A good data structure in the population is necessary to allow the separation of both genetic effects. Results for these two traits measured at weaning suggested the existence of very flat likelihood functions which means that the data provides limited information. Two causes are usually given as the reasons for such likelihood functions: the small number of records, and, in the case of models including maternal effects, 
the small number of animals having simultaneously their own record and the performance records of their offspring. Both causes could be argued in the analysed population as shown in Table 1, but most of the data based on control of performances are similar.

When the covariance between both maternal and direct genetic effects is close to zero, as described before for birth weight, the estimates for the other components seem to be very robust. This is in close agreement with those models assuming this covariance to be nil. A considerable debate exists about the validity of results when this covariance component is not negligible (SHI et al. 1993, MEYER 1994) as occurs in the case of the other two traits analysed.

On the other hand, an important reason for the questionable estimates lies in the number of records and structure of the data set, problems which can only be corrected after years of collecting records. This makes the choice of reliable genetic parameters to evaluate the animals very difficult at present.

An important alternative to the animal model can be found in a sire-maternal grandsire model with the dam nested within the maternal grandsire in populations where the lack of information is a limiting factor. The sire model ignores all the relationships between cows other than those coming from the sires, assuming that there is no selection via the dams, and assuming also that all the matings are random, thus underestimating the additive genetic variance (SORENSEN and KENNEDY, 1984). However, the sire model has the advantage of increasing the information per animal which could be useful in populations with low information such as the analysed data set.

At present, there is a general agreement about the deficiencies of the models involving maternal effects. Some environmental covariances related to the maternal effect, present in several data sets, are not included in the current models. Such covariances seem to influence the final estimates. These covariances could be more reasonably treated by splitting the maternal effect in the maternal grandsire and the dam effects in the model. So, a sire model was used to confirm or refute the results obtained by the use of the animal model.

Results from the sire models were similar to those of the animal models for the birth weight trait but not so for the other two traits where the maternal component was clearly underestimated when compared to the animal models. It seems that, in the animal models, the maternal component was forced to be higher by the negative correlation between both additive and maternal genetic effects. In addition, the phenotypic variance was somewhat higher when this covariance component was important, in both animal and sire models.

Summarizing, the results for birth weight under an animal model seem to be very reasonable but different treatment should be given to the other two traits. For the first trait, the model 2 agrees with models 3 and 4, given that the direct-maternal covariance component obtained in the last two models was nearly zero as assumed in model 2 . Traits measured at weaning should have an important maternal variability. Model 2 gave a low maternal component and models 3 and 4, accounting for a direct-maternal genetic covariance, gave high and negative estimates of these covariances causing heritabilities to rise to 0.60 and 0.50 , respectively, for weaning weight and pre-weaning average daily gain, increasing also the maternal heritability. These estimates may not be very reliable, even when similar differences between models have been described by other authors in other breeds (MEYER 1992, 1993, 1994).

Different interpretations have been given to this type of result. FOULLEY and LEFORT (1978) suggested that the estimation of maternal effects and their respective genetic parameters is inherently problematic and, due to the confusion of direct and maternal effects, subject to large sampling errors. MEYER (1994) attributed them also, to a large extent, to sampling covariation whilst SHI et al. (1993) thought there could also be a covariance between maternal and direct environments. ROBINSON (1996) showed a dramatic increase in likelihood along with a substantial reduction in the estimate of the direct-maternal genetic covariance when additional random effects such as sire $\times$ herd effect or a regression on maternal phenotype where included in the model of analysis. 
Table 2. Estimated parameters from all the models and difference in likelihood value to the simplest one (significance level: ${ }^{* * *} \mathbf{p}<0.005,{ }^{* *} \mathbf{p}<0.01,{ }^{*} \mathbf{p}<0.05$, ${ }^{\mathrm{n}} \mathbf{p}>\mathbf{0 . 0 5}$ ). 'Best' estimates in terms of

likelihood values under an animal and sire model are in bold

\begin{tabular}{|c|c|c|c|c|c|c|c|}
\hline Traits & $h^{2}$ & $m^{2}$ & $\sigma_{l m} / \sigma^{2}$ & $r_{a m}$ & $c^{2}$ & $\sigma_{2}$ & Difference \\
\hline \multicolumn{8}{|l|}{ Birth weight } \\
\hline Model 1 & 0.57 & - & - & - & - & 54.17 & 0 \\
\hline Model 2 & 0.32 & 0.13 & - & - & - & 52.01 & $33.091 * * *$ \\
\hline Model 3 & 0.33 & 0.14 & -0.01 & -0.06 & - & 52.06 & $33.164^{\mathrm{n}}$ \\
\hline Model 4 & 0.34 & 0.09 & -0.02 & -0.13 & 0.06 & 52.00 & $36.770 * * *$ \\
\hline Model 5 & 0.37 & - & - & - & - & 49.38 & 0 \\
\hline Model 6 & 0.33 & 0.20 & 0.02 & 0.09 & - & 50.28 & $32.078 * * *$ \\
\hline \multicolumn{8}{|c|}{ Weaning weight } \\
\hline Model 1 & 0.52 & - & - & - & - & 1326.35 & 0 \\
\hline Model 2 & 0.45 & 0.04 & - & - & - & 1315.23 & $2.750 *$ \\
\hline Model 3 & 0.60 & $\mathbf{0 . 3 0}$ & -0.31 & -0.73 & - & 1340.91 & $10.969 * * *$ \\
\hline Model 4 & 0.60 & 0.30 & -0.31 & -0.73 & 0.00 & 1341.94 & $10.969^{\mathrm{n}}$ \\
\hline Model 5 & 0.60 & - & - & - & - & 1274.93 & 0 \\
\hline Model 6 & 0.58 & 0.06 & -0.12 & -0.65 & - & 1277.31 & $5.856 * * *$ \\
\hline Model 7 & 0.57 & 0.04 & -0.11 & -0.73 & 0.03 & 1276.55 & $11.336 * * *$ \\
\hline \multicolumn{8}{|c|}{ Average daily gain } \\
\hline Model 1 & 0.52 & - & - & - & - & 38693.40 & 0 \\
\hline Model 2 & 0.33 & 0.05 & - & - & - & 38251.65 & $4.233^{*}$ \\
\hline Model 3 & 0.49 & 0.37 & -0.37 & -0.87 & - & 39160.81 & $16.220 * * *$ \\
\hline Model 4 & 0.50 & 0.37 & -0.37 & -0.87 & 0.00 & 39145.44 & $16.220^{\mathrm{n}}$ \\
\hline Model 5 & 0.52 & - & - & - & - & 37992.71 & 0 \\
\hline Model 6 & 0.51 & 0.16 & -0.21 & -0.75 & - & 38043.57 & $4.179 *$ \\
\hline Model 7 & 0.49 & 0.13 & -0.20 & -0.78 & 0.06 & 38023.41 & $10.439 * * *$ \\
\hline
\end{tabular}

Likelihood values were used to choose among estimates coming from different models of analysis, although sometimes it is difficult to make a good choice (SWALVE 1993). Table2 shows the difference of the log likelihood under model 1 from the respective value under models 2 to 4 for the three traits studied. For the single parameter case, when comparing model 1 and 2 or model 2 and 3 or model 3 and 4, a likelihood ratio test can be applied by multiplying the difference as given in Table 2 by -2 and comparing it to a Chi-square test statistic with one degree of freedom (SWALVE 1993). According to this test, the significance of the differences are also shown in Table 2. Regarding this criterion, the 'best' animal model and the 'best' sire model were chosen according to the significant difference in the likelihood values (Table 2).

When the model 7 was fitted for the birth weight trait, a dramatic increase in likelihood was shown, and similar estimates to the equivalent animal model (model 4) were obtained.

When comparing results from the 'best' animal model with those of the 'best' sire model, the latter led to lower maternal heritabilities. Differences found for the other parameters estimated can be explained by the related underestimation of the maternal genetic component and do not seem to be very important. Thus, sire models showed better performance to analyse a poorly -structured data set when maternal effects are fitted in the models.

To conclude, difficulties for the choice of the correct model were found similar to comparative analysis between models involving maternal effects. Again, further research about these kind of models seems to be needed.

\section{Summary}

Estimates of variance components for birth weight, weaning weight and average daily gain were obtained comparing different animal and sire univariate models for an important local beef cattle breed. 
Problems encountered with models involving maternal effects were discussed. Direct and maternal heritabilities were respectively 0.32 and 0.13 for birth weight, 0.60 and 0.30 for weaning weight and 0.49 and 0.37 for average daily gain. The correlation between direct and maternal genetic effects was not important for birth weight, but high and negative for weaning weight $(-0.73)$, and average daily gain $(-0.87)$, in close agreement with the most recent estimates in other breeds.

\section{Zusammenfassung}

Schdtzung Direkter and Materna-Genetischer Parameter yon Kdlhermerkmalen in der "Asturiana de los Valles" Fleischrinderrasse mittels Tier- and Vatermodellen.

Varianzkomponentenschátzungen fur Geburtsgewicht Absatzgewicht and Durchschnittstageszuwachs wurden zwischen verschiedenen univariablen Tier- and Vatermodellen bei dieser wichtigen lokalen Rinderrassc verglichen.Die durch Einbcziehung maternaler Wirkungen entstandenen Probleme wcrden diskutiert. Direkte and maternale Heritabilitátswcrte sind für Geburtsgewicht 0.32 and 0.13 , fur Absatzgewicht 0.60 and 0.30 and für Durchschnittstageszuwachs 0.49 and 0.37 . Die Korrelation zwischen direkten and maternalen Wirkungen war für Geburtsgewicht unwichtig, abet hoch negativ für Absatzgewicht $(-0.73)$ and for Zuwachs $(-0.87)$, was mit zahlreichen neueren Schätzungen übereinstimmt.

\section{Acknowledgements}

This work was partially supported by a grant from the CICYT, No.AGF92-0852 and from ASEAVA. The authors would like to tank Karin Meyer for the use of her DFREML program.

\section{References}

Cantet, R. J. C.; Ganola, D.; MiszTai.,I.; Fernando R. L., 1993: Estimates of dispersion parameters and of genetic and environmental trends for weaning weight in Angus cattle using a maternal animal model with genetic grouping. Livest. Prod. Sci. 34: 203-212.

CANON J.; Gutierrez, J. P.; DUnNer, S.; GOYACHE, F.; VAlleJo, M.,1994: Herdbook analyses of the Asturiana beef cattle breeds. Genet. Scl. Evol. 26: 65-75.

FOULLEy, J. L.; LEFORT, G., 1978: Methodes d'estimation des effects directs et maternels en selection animale. Ann. Genet. Sel. Anim. 10: 475-496.

GROENEVELD, E.,1991: Estimation of 60 Covariance Components Using a Derivative Free Multivariate REML Procedure. In: Proc. 63rd meeting Genetisch-Statische Ausschuß der DGfZ. pp. 15.

MEYER, K., 1991: Estimating variances and covariances for multivariate Animal Models by Restricted Maximum Likelihood. Genet Sel. Evol. 23: 67-83.

-, 1992: Variance components due to direct and maternal effects for growth traits of Australian beef cattle. Livest. Prod. Sci. 31: 179-204.

-, 1993: Covariance matrices for growth traits of Australian Polled Hereford cattle. Anim. Prod. 57: 37-45.

-, 1994: Estimates of direct and maternal correlations among growth traits in Australian beef cattle. Livest. Prod. Sci. 38: 91-105.

MoHIUDDIN G., 1993: Estimates of genetic and phenotypic parameters of some performance traits in beef cattle. Anim. Breed. Abstr. 61: 495-522.

RoBINSON, D. L., 1996: .Estimation and interpretation of direct and maternal genetic parameters for weights of Australian Angus cattle. Lives. Prod. Sci. 45: 1-11.

SHI, M. J.; LALOË, D.; MÉNISSIER, F.; REMAND, G., 1993: Estimation of genetic parameters of preweaning performance in the French Limousin cattle breed. Genet. Sel. Evol. 25: 177-189.

SORENSEN, D.; KENNEDY B.W., 1984: Estimation of Genetic Variances from unselected populations. J. Animal Sci. 59: 1213-1223.

SWALVE, H. H., 1993: Estimation of direct and maternal (co)variance components for growth traits in Australian Simmental beef cattle. J. Anim. Breed. Genet. 110: 241-252.

TAWAH, C. L.; MBAH, D. A.; ReGE, J. F. O.; OUMATE, H., 1993: Genetic evaluation of birth and weaning weight of Gudali and two breed synthetic Wakwa beef cattle populations under selection in Cameroon: genetic and phenotypic parameters. Anm. Prod. 57: 73-79.

Vallejo, M.; Gutierrez, J. P.; Cima, M.; CAnON, J.; Alonso, L.; Revuelta, R.; Goyache, F., 1992: Carcass characteristics of Asturiana bovine breeds. III. Asturiana de los Valle's quantitative evaluation and prediction of carcass composition. Arch. Zootec. 42: 29-40.

WALDRON, D. F.; MORRIS, C. A.; BAKER, R. L.; JOHNSON, D. L., 1993: Maternal effects for growth traits in beef cattle. Lives. Prod. Sci. 34: 57-70. 